\title{
EXPOSIÇÃO DA EQUIPE DE ENFERMAGEM AOS RISCOS BIOLÓGICOS EM UNIDADE DE TERAPIA INTENSIVA: REVISÃO INTEGRATIVA
}

\section{Exposure of nursing team to biological risk in intensive care unit: integrative review}

Katherine Kristinne de Oliveira Moraes ${ }^{1}$, Luana Ferreira de Almeida ${ }^{2}$, Lucilene Pereira Mesquita da Silva ${ }^{3}$, Marta Lucia Garcia Fernandes dos Santos ${ }^{4}$, Edvânia Soares da Silva $^{5}$, Claudemir Santos de Jesus ${ }^{6}$

${ }^{1}$ Enfermeira, Especialista em Enfermagem do trabalho pela Universidade Veiga de Almeida.

2 Enfermeira, Doutora em Educação em Saúde pela UFRJ. Professora Adjunta do Departamento de Enfermagem Médico-Cirúrgica da Faculdade de Enfermagem/UERJ.

${ }^{3}$ Acadêmica de Enfermagem do $7^{\circ}$ período pela Faculdade de Duque de Caxias.

${ }^{4}$ Acadêmica de Enfermagem do 8o período pela Faculdade de Duque de Caxias.

${ }^{5}$ Enfermeira, Universidade Estadual do Rio de Janeiro (UERJ).

${ }^{6}$ Enfermeiro, Mestre em Enfermagem pela EEAN/UFRJ, Professor Convidado pela Universidade Veiga de Almeida.

\section{Endereço para correspondência:}

Katherine Kristinne de Oliveira Moraes

Rua Carlos Vasconvelos, n. 59 A, Apto 202, Tijuca CEP: 20521-050

Telefone: (21) 98598-8522

Email: katherine_kom@hotmail.com 


\title{
Resumo
}

Introdução: Em uma Unidade de Terapia Intensiva, os profissionais de saúde, principalmente a equipe de Enfermagem, estão constantemente no exercício da prestação de assistência aos pacientes críticos, com exposição aos riscos biológicos e de doenças, devido ao meio insalubre do ambiente de alta complexidade. Objetivo: Identificar as ações educativas para a diminuição das causas de riscos de acidentes nos profissionais de Enfermagem na Unidade de Terapia Intensiva. Metodologia: Esta pesquisa é do tipo Revisão Integrativa, através de busca de artigos no portal da Biblioteca Virtual de Saúde, nas bases de dados LILACS e BDENF, no período de 2005 a 2014. Resultados: A coleta de dados foi realizada no portal da Biblioteca Virtual de Saúde, com a questão de pesquisa: quais as ações educativas para a diminuição dos riscos de acidentes biológicos nos profissionais de saúde na Unidade de Terapia Intensiva? Assim, foi identificado na busca o quantitativo de 06 artigos na LILACS e 03 na BDENF, no total de 09 artigos. Conclusão: As informações colhidas nesta revisão integrativa mostram que a exposição aos materiais biológicos e os acidentes ocupacionais nos profissionais de Enfermagem são passíveis de prevenção e diminuição dos acidentes de trabalho através das orientações e treinamentos para os profissionais da equipe de Enfermagem.

Palavras-Chave: Enfermagem; Terapia Intensiva; Riscos Biológicos; Educação.

\begin{abstract}
Introduction: In an intensive care unit, health professionals, especially nursing staff, are constantly in the course of providing assistance to critically ill patients being exposed to biological hazards and diseases due to unhealthy means of highly complex environment. Objective: To identify the educational actions to reduce the causes of risk of accidents in nursing professionals in the Intensive Care Unit. Methodology: This research is the type Integrative Review, through search articles on the website of Virtual Health Library, in LILACS and BDENF databases, from 2005 to 2014. Results: The data collection was performed in the portal Library virtual health, with research question: which educational actions to reduce biological risks of accidents in health professionals in the Intensive Care Unit? Thus, it was identified in the search the quantity of 06 articles in LILACS and 03 in BDENF, on totality of 09 articles.
\end{abstract}




\section{Saúde Funcional}

Conclusion: The information gathered in this integrative review, show that exposure to biological materials and related injuries in nursing professionals are preventable and reduction of occupational accidents through the guidelines and training for professionals in the nursing team.

Keywords: Nursing; Intensive Care; Biological Hazards; Education.

\section{INTRODUÇÃO}

O ambiente hospitalar é considerado insalubre por viabilizar muitos procedimentos que oferecem riscos de acidentes à equipe de saúde, por ter o agrupamento dos indivíduos portadores de doenças infectocontagiosas e/ou multirresistentes ${ }^{1,2}$.

A partir de 1980, após a descoberta do vírus da síndrome da imunodeficiência adquirida, ocorreram preocupações atribuídas ao risco de contaminação dos profissionais de saúde por exposição dos materiais e agentes biológicos responsáveis por infecções, tanto que o Centers for Disease Control and Prevention (CDC) introduziu as "Precauções Universais", que enfatizam o uso de luvas em contato direto com sangue, fluidos corporais e vias aéreas ${ }^{1,2}$.

Este estudo emergiu da vivência de um dos autores na Unidade de Terapia Intensiva, frente à atuação das equipes, principalmente dos Enfermeiros que são constantemente expostos aos riscos biológicos e às substâncias químicas, que pode trazer consequências físicas aos profissionais da Enfermagem.

Assim, o Enfermeiro do trabalho deve atuar na promoção e preservação da integridade física e mental do funcionário durante o exercício diário, por meio de análise crítica reflexiva no local de trabalho, que busque detectar fatores que interferem no bem estar ${ }^{3}$.

Desta forma, o Enfermeiro intensivista demanda conhecimentos específicos à utilização de materiais de insumos para procedimentos na clientela, tais como kits de punções e manipulação de equipamentos, que aumentam o risco de exposição das equipes em um ritmo de atividade intenso, tanto que os riscos ocupacionais nos trabalhadores de Enfermagem estariam relacionados com o cuidado e às próprias 


\section{Saúde Funcional}

características dos pacientes críticos, como a presença de sangue, procedimentos de sondagem, cateterismo e intervenções com materiais perfurocortantes ${ }^{4,2}$.

Devido aos riscos de exposição dos profissionais durante a assistência direta, foi aplicado ao meio laboral a Norma Regulamentadora 32 (NR-32) com a finalidade de estabelecer diretrizes básicas à implementação de medidas de proteção à segurança dos trabalhadores nos serviços de saúde, bem como os que exercem atividades de promoção e assistência em geral nas instituições de saúde.

Mediante a essas questões supracitadas, a identificação das causas precocemente são necessárias para ter caráter preventivo, cujas estratégias educativas servem como alerta dos fatores relacionados em lócus, para possibilitar a diminuição das ocorrências de doenças e acidentes no ambiente de trabalho, frente à temática de saúde do trabalhador ${ }^{3,5}$.

Contudo, o presente estudo objetivou: identificar as ações educativas para a diminuição das causas de riscos de acidentes nos profissionais de Enfermagem na Unidade de Terapia Intensiva.

\section{MÉTODO E RESULTADO}

A linha metodológica desenvolvida seguiu a abordagem qualitativa num estudo de Revisão Integrativa, que teve como finalidade obter profundo entendimento de um determinado fenômeno, com base na reunião e sistematização de estudos anteriores sobre um assunto a partir dos objetivos, materiais, métodos e construir uma conclusão dos resultados evidenciados, por meio de sistematização do método em seis etapas ${ }^{6}$.

Para nortear este estudo, na primeira etapa confeccionamos a questão de pesquisa: quais as ações educativas para a diminuição das causas de riscos de acidentes nos profissionais de Enfermagem na Unidade de Terapia Intensiva?

Para a amostragem das produções, a segunda etapa foi realizada, com base nas buscas na Biblioteca Virtual de Saúde, nas bases de dados LILACS (Literatura Latino-Americana e do Caribe em Ciências da Saúde) e BDENF (Base de Dados de Enfermagem) (Quadro 1), cujos critérios de inclusão envolveram: artigos completos em português no período de 2005 a 2014, com os descritores: Enfermagem; Terapia Intensiva; Riscos Biológicos; Educação. 
Os critérios de exclusão definidos foram: estudos incompletos, como projetos e resumos, pesquisas em outros idiomas, fora do recorte temporal e aqueles que não contemplaram a temática, constando ou não os descritores.

Quadro 1. Cruzamento dos descritores na BVS.

\begin{tabular}{|c|c|c|c|}
\hline \multirow{2}{*}{ DESCRITORES } & $\begin{array}{c}\text { BASE DE } \\
\text { DADOS }\end{array}$ & TOTAL & SELEÇÃO \\
\hline "Riscos Biológicos" AND "Educação" & LILACS & 53 & 04 \\
\cline { 2 - 4 } & BDENF & 25 & 03 \\
\hline "Enfermagem" AND “Terapia Intensiva" AND & LILACS & 10 & 02 \\
\cline { 2 - 4 } "Riscos Biológicos" & BDENF & 05 & 0 \\
\hline \multicolumn{2}{|c|}{ TOTAL } & 93 & 09 \\
\hline
\end{tabular}

$\mathrm{Na}$ "busca avançada", foram cruzados os descritores "Riscos Biológicos" e "Educação". Na base de dados LILACS foram encontrados inicialmente 53 artigos. Após utilizar os filtros "artigos disponíveis em português" e "assunto" da revista Enfermagem e Educação, obteve-se como resultado 04 artigos.

Já na base de dados BDENF foram encontrados 25 artigos. Após o uso dos filtros "artigos disponíveis, idioma português" e o "assunto principal: riscos ocupacionais, exposição a agentes biológicos nocivos, saúde do trabalhador, exposição ocupacional, acidentes de trabalho, pessoal da saúde, equipamentos de proteção, fatores de risco, acidentes e eventos biológicos", resultaram 07 artigos nessa base, sendo que 04 haviam sido encontrados na base de dados LILACS, com o resultado de 03 produções.

Já com os descritores "Enfermagem"; "Terapia Intensiva”; "Riscos Biológicos", que utilizaram a "busca avançada" e a palavra AND na base de dados LILACS, foram encontrados 10 artigos e, após os filtros, restaram 02 artigos relacionados com a temática e os mesmos na BDENF.

Dessa forma, com a busca foi identificado o quantitativo de 06 artigos na LILACS e 03 na BDENF, no total de 09 artigos, que foram submetidos à análise de forma sistemática através de um instrumento na terceira etapa da revisão, conforme abaixo (Quadro 2): 
Quadro 2: Artigos encontrados nas Bases de Dados LILACS e BDENF.

\begin{tabular}{|c|c|c|c|c|c|c|}
\hline Base & Ano & Periódico & $\begin{array}{c}\text { Qualis } \\
2014\end{array}$ & Autor & Titulo & $\begin{array}{l}\text { Tipo de } \\
\text { Produção }\end{array}$ \\
\hline LILACS & 2008 & $\begin{array}{c}\text { Esc } \\
\text { Enferm. } \\
\text { Anna Nery }\end{array}$ & B1 & $\begin{array}{l}\text { CASTRO; } \\
\text { FARIAS }\end{array}$ & $\begin{array}{l}\text { A produção científica } \\
\text { sobre riscos } \\
\text { ocupacionais a que } \\
\text { estão expostos os } \\
\text { trabalhadores de } \\
\text { Enfermagem. }\end{array}$ & $\begin{array}{c}\text { Artigo } \\
\text { Original }\end{array}$ \\
\hline LILACS & 2011 & $\begin{array}{l}\text { Rev. } \\
\text { Enferm. } \\
\text { UERJ }\end{array}$ & B1 & $\begin{array}{c}\text { CÂMARA et } \\
\text { al. }\end{array}$ & $\begin{array}{c}\text { Investigação de } \\
\text { acidentes biológicos } \\
\text { entre profissionais da } \\
\text { equipe multidisciplinar } \\
\text { de um hospital. }\end{array}$ & $\begin{array}{c}\text { Artigo } \\
\text { Original }\end{array}$ \\
\hline LILACS & 2010 & $\begin{array}{l}\text { Ciênc. } \\
\text { Cuid. } \\
\text { Saúde }\end{array}$ & B2 & $\begin{array}{l}\text { RIBEIRO et } \\
\text { al. }\end{array}$ & $\begin{array}{l}\text { Influência da exposição } \\
\text { a material biológico na } \\
\text { adesão ao uso de } \\
\text { equipamentos de } \\
\text { proteção individual. }\end{array}$ & $\begin{array}{c}\text { Artigo } \\
\text { Original }\end{array}$ \\
\hline LILACS & 2011 & $\begin{array}{l}\text { Brazilian } \\
\text { Journal of } \\
\text { Nursing }\end{array}$ & B2 & WALL et al. & $\begin{array}{c}\text { As crenças dos } \\
\text { trabalhadores de saúde } \\
\text { nos acidentes de } \\
\text { trabalho com exposição } \\
\text { a fluido biológico: } \\
\text { pesquisa descritiva. }\end{array}$ & $\begin{array}{c}\text { Artigo } \\
\text { Original }\end{array}$ \\
\hline LILACS & 2007 & $\begin{array}{c}\text { Esc } \\
\text { Enferm. } \\
\text { Anna Nery }\end{array}$ & B1 & $\begin{array}{l}\text { CORREA; } \\
\text { DONATO }\end{array}$ & $\begin{array}{l}\text { Biossegurança em uma } \\
\text { unidade de terapia } \\
\text { intensiva a percepção da } \\
\text { equipe de Enfermagem }\end{array}$ & $\begin{array}{c}\text { Artigo } \\
\text { Original }\end{array}$ \\
\hline LILACS & 2008 & $\begin{array}{l}\text { Cienc. } \\
\text { Cuid. } \\
\text { Saúde }\end{array}$ & B2 & LEITÃO et al. & $\begin{array}{l}\text { Saúde ocupacional: } \\
\text { analisando os riscos } \\
\text { relacionados à equipe de } \\
\text { Enfermagem numa } \\
\text { unidade de terapia } \\
\text { intensiva }\end{array}$ & $\begin{array}{c}\text { Artigo } \\
\text { Original }\end{array}$ \\
\hline BDENF & 2011 & $\begin{array}{c}\text { Cuidado é } \\
\text { Fundamental } \\
\text { Online }\end{array}$ & B2 & $\begin{array}{c}\text { SILVA; } \\
\text { CORTEZ; } \\
\text { VALENTE }\end{array}$ & $\begin{array}{c}\text { Acidentes com materiais } \\
\text { perfuro cortantes e } \\
\text { biológicos no ambiente } \\
\text { hospitalar: análise da } \\
\text { exposição ao risco e } \\
\text { medidas preventivas }\end{array}$ & $\begin{array}{l}\text { Artigo } \\
\text { Original }\end{array}$ \\
\hline BDENF & 2012 & $\begin{array}{c}\text { Cuidado é } \\
\text { Fundamental } \\
\text { Online }\end{array}$ & B2 & $\begin{array}{l}\text { METELLO; } \\
\text { VALENTE }\end{array}$ & $\begin{array}{c}\text { A importância de } \\
\text { medidas de } \\
\text { biossegurança como } \\
\text { prevenção de acidentes } \\
\text { do trabalho através da } \\
\text { identificação de riscos }\end{array}$ & $\begin{array}{l}\text { Artigo } \\
\text { Original }\end{array}$ \\
\hline
\end{tabular}


Artigo de Revisão

Saúde Funcional

\begin{tabular}{|l|l|l|l|l|c|c|}
\hline Base & Ano & Periódico & $\begin{array}{c}\text { Qualis } \\
\mathbf{2 0 1 4}\end{array}$ & Autor & Titulo & $\begin{array}{c}\text { Tipo de } \\
\text { Produção }\end{array}$ \\
\hline BDENF & 2008 & $\begin{array}{c}\text { CuidArte } \\
\text { Enfermagem }\end{array}$ & B5 & $\begin{array}{c}\text { MAGAGNINI; } \\
\text { MIOTTO; } \\
\text { SERRADILHA }\end{array}$ & $\begin{array}{c}\text { Acidentes de trabalho } \\
\text { com material biológico } \\
\text { entre os profissionais de } \\
\text { saúde }\end{array}$ & $\begin{array}{c}\text { Artigo } \\
\text { Original }\end{array}$ \\
\hline
\end{tabular}

Expondo uma visão geral dos artigos, considerando os anos de 2005 a 2014, o período de tempo onde foram encontradas mais publicações foram nos anos de 2008 (03), 2011 (03), 2007 (01), 2010 (01) e 2012 (01). Quanto à origem das publicações, 04 artigos foram originários do estado do Rio de Janeiro, sendo os demais dos estados de Pernambuco, Goiás, Paraná, Ceará e São Paulo.

Dentre os periódicos em que os artigos foram publicados, dois pertencem à "Escola Anna Nery Revista de Enfermagem" (B1), dois à "Ciência, Cuidado e Saúde" (B2) e dois à "Cuidado é Fundamental" (B2). As demais, Online "Brazilian Journal of Nursing" (B2), "CuidArte Enfermagem" (B5) e "Revista Enfermagem UERJ" (B1), contém 01 publicação cada.

Os 09 artigos selecionados foram analisados na quarta etapa (Quadro 3), para a verificação da autenticidade, qualidade metodológica, importância das informações e representatividade.

Quadro 3. Análise dos Estudos Coletados.

\begin{tabular}{|c|c|c|}
\hline Título & Objetivos & Resultados \\
\hline $\begin{array}{c}\text { A produção } \\
\text { científica sobre } \\
\text { riscos } \\
\text { ocupacionais a } \\
\text { que estão } \\
\text { expostos os } \\
\text { trabalhadores de } \\
\text { Enfermagem }\end{array}$ & $\begin{array}{c}\text { Levantar a produção científica } \\
\text { dos riscos ocupacionais nos } \\
\text { trentificar a abordagem (objetiva } \\
\text { ou subjetiva) acerca desses } \\
\text { riscos e analisar os riscos }\end{array}$ & $\begin{array}{c}\text { Percebeu-se reduzida ênfase } \\
\text { dispensada à subjetividade do } \\
\text { trabalhador de enfermagem associada à } \\
\text { temática estudada, sugerindo lacuna } \\
\text { nesta área de conhecimento. }\end{array}$ \\
\hline $\begin{array}{c}\text { Influência da } \\
\text { exposição a }\end{array}$ & $\begin{array}{c}\text { Avaliar se a exposição a material } \\
\text { biológico é um fator }\end{array}$ & $\begin{array}{c}\text { A experiência da exposição influencia na } \\
\text { mudança de comportamento para a }\end{array}$ \\
\hline
\end{tabular}




\begin{tabular}{|c|c|c|}
\hline Título & Objetivos & Resultados \\
\hline $\begin{array}{l}\text { material biológico } \\
\text { na adesão ao uso } \\
\text { de equipamentos } \\
\text { de proteção } \\
\text { individual }\end{array}$ & $\begin{array}{l}\text { determinante para a adesão ao } \\
\text { uso do equipamento de proteção } \\
\text { individual por parte dos } \\
\text { trabalhadores de enfermagem. }\end{array}$ & $\begin{array}{l}\text { adesão ao equipamento de proteção, } \\
\text { sendo que esse comportamento é } \\
\text { individual e sofre influências de outros } \\
\text { fatores, como ausência ou inadequação } \\
\text { do equipamento de proteção individual, } \\
\text { sobrecarga de trabalho, pressa e } \\
\text { situações de emergência. }\end{array}$ \\
\hline $\begin{array}{l}\text { As crenças dos } \\
\text { trabalhadores de } \\
\text { saúde nos } \\
\text { acidentes de } \\
\text { trabalho com } \\
\text { exposição a fluido } \\
\text { biológico: } \\
\text { pesquisa } \\
\text { descritiva }\end{array}$ & $\begin{array}{l}\text { Identificar o conhecimento sobre } \\
\text { as consequências da exposição } \\
\text { a fluido biológico e sobre o } \\
\text { protocolo de monitoramento pós- } \\
\text { acidente, e conhecer as crenças } \\
\text { que influenciam essa adesão. }\end{array}$ & $\begin{array}{l}\text { Há preocupação dos trabalhadores em } \\
\text { contrair AIDS e hepatite; referem } \\
\text { agregar comportamentos preventivos ao } \\
\text { risco após o evento; percebem o } \\
\text { acompanhamento sorológico como } \\
\text { benefício; reconhecem o acidente como } \\
\text { gerador de estresse emocional e relatam } \\
\text { não haver investimentos das instituições } \\
\text { para promover o conhecimento e evitar } \\
\text { acidentes com exposição biológica. }\end{array}$ \\
\hline $\begin{array}{l}\text { Biossegurança } \\
\text { em uma unidade } \\
\text { de terapia } \\
\text { intensiva a } \\
\text { percepção da } \\
\text { equipe de } \\
\text { Enfermagem }\end{array}$ & $\begin{array}{l}\text { Descrever as medidas de } \\
\text { biossegurança adotadas pela } \\
\text { equipe de enfermagem durante } \\
\text { a assistência prestada em UTI; } \\
\text { identificar a percepção da equipe } \\
\text { de enfermagem acerca da } \\
\text { importância da adoção e } \\
\text { implementação de medidas de } \\
\text { biossegurança durante esta } \\
\text { assistência e analisar as } \\
\text { possibilidades de implementação } \\
\text { por esta equipe de medidas de } \\
\text { biossegurança durante esta } \\
\text { assistência. }\end{array}$ & $\begin{array}{l}\text { Observou a necessidade de adoção de } \\
\text { medidas voltadas para a educação } \\
\text { permanente da equipe de enfermagem } \\
\text { no que se refere às normas de } \\
\text { biossegurança, visando também à } \\
\text { proteção e à segurança do cliente e a de } \\
\text { outros profissionais que exercem } \\
\text { atividades naquele contexto laboral. }\end{array}$ \\
\hline
\end{tabular}




\begin{tabular}{|c|c|c|}
\hline Título & Objetivos & Resultados \\
\hline $\begin{array}{l}\text { Saúde } \\
\text { ocupacional: } \\
\text { analisando os } \\
\text { riscos } \\
\text { relacionados à } \\
\text { equipe de } \\
\text { Enfermagem } \\
\text { numa unidade de } \\
\text { terapia intensiva }\end{array}$ & $\begin{array}{l}\text { Analisar os riscos ocupacionais } \\
\text { a que estão expostos os } \\
\text { profissionais de enfermagem } \\
\text { que trabalham numa UTI. }\end{array}$ & $\begin{array}{l}\text { Os riscos ocupacionais expostos a } \\
\text { equipe de enfermagem na UTI estavam } \\
\text { relacionados ao excesso de ruídos na } \\
\text { unidade, à temperatura inadequada do } \\
\text { ambiente, à inobservância do controle de } \\
\text { gases e vapores, à falta de pausas } \\
\text { sistemáticas para descanso e à } \\
\text { exposição diária a agentes biológicos, } \\
\text { fatores psicossociais e de natureza } \\
\text { ergonômica que são significativos para o } \\
\text { surgimento de problemas de saúde. }\end{array}$ \\
\hline $\begin{array}{l}\text { Acidentes com } \\
\text { materiais perfuro } \\
\text { cortantes e } \\
\text { biológicos no } \\
\text { ambiente } \\
\text { hospitalar: análise } \\
\text { da exposição ao } \\
\text { risco e medidas } \\
\text { preventivas }\end{array}$ & $\begin{array}{l}\text { Identificar os riscos ocupacionais } \\
\text { e pontuar as causas de } \\
\text { acidentes com materiais } \\
\text { perfurocortantes e biológicos } \\
\text { entre os profissionais de } \\
\text { enfermagem no ambiente } \\
\text { hospitalar, e descrever medidas } \\
\text { preventivas a serem adotadas } \\
\text { pelos enfermeiros do trabalho } \\
\text { para reduzir tais acidentes na } \\
\text { referida categoria profissional. }\end{array}$ & $\begin{array}{l}\text { Identificou como riscos ocupacionais a } \\
\text { manipulação de agulhas ou cateteres } \\
\text { intravenosos e o local de descarte e } \\
\text { riscos específicos da atividade laboral. } \\
\text { Como medidas preventivas para reduzir } \\
\text { a ocorrência de acidentes destaca-se o } \\
\text { uso de EPIs e capacitação técnica para } \\
\text { os profissionais de enfermagem. }\end{array}$ \\
\hline $\begin{array}{l}\text { Acidentes de } \\
\text { trabalho com } \\
\text { material biológico } \\
\text { entre os } \\
\text { profissionais de } \\
\text { saúde }\end{array}$ & $\begin{array}{l}\text { Caracterizar os acidentes } \\
\text { ocupacionais com material } \\
\text { biológico no período de } 2000 \text { - } \\
\text { 2006, em dois hospitais-escola } \\
\text { do interior paulista. }\end{array}$ & $\begin{array}{l}\text { Os dados encontrados inferem que } \\
\text { acidentes poderiam ser evitados, se } \\
\text { observadas regras simples de } \\
\text { segurança. }\end{array}$ \\
\hline $\begin{array}{l}\text { Investigação de } \\
\text { acidentes } \\
\text { biológicos entre }\end{array}$ & $\begin{array}{c}\text { Analisar a ocorrência de } \\
\text { acidentes com material biológico } \\
\text { entre profissionais de uma }\end{array}$ & $\begin{array}{l}\text { Apontou que os técnicos de enfermagem } \\
\text { são mais expostos (50\%), seguida dos } \\
\text { auxiliares de enfermagem }(25,53 \%) \text {, e a }\end{array}$ \\
\hline
\end{tabular}


Artigo de Revisão

Saúde Funcional

\begin{tabular}{|c|c|c|}
\hline Título & Objetivos & Resultados \\
\hline $\begin{array}{l}\text { profissionais da } \\
\text { equipe } \\
\text { multidisciplinar de } \\
\text { um hospital }\end{array}$ & $\begin{array}{l}\text { unidade hospitalar de } \\
\text { atendimento geral. }\end{array}$ & $\begin{array}{l}\text { principal causa foi devido ao descarte } \\
\text { inadequado de material perfurocortante } \\
(43,62 \%) \text {, seguida do procedimento de } \\
\text { punção venosa periférica }(15,96 \%) \text { e } \\
\text { manuseio do lixo }(12,77 \%) \text {. }\end{array}$ \\
\hline $\begin{array}{l}\text { A importância de } \\
\text { medidas de } \\
\text { biossegurança } \\
\text { como prevenção } \\
\text { de acidentes do } \\
\text { trabalho através } \\
\text { da identificação } \\
\text { de riscos } \\
\text { biológicos no } \\
\text { mapa de risco }\end{array}$ & $\begin{array}{l}\text { Identificar na literatura os riscos } \\
\text { existentes no ambiente de } \\
\text { trabalho através do mapa de } \\
\text { risco; descrever as medidas de } \\
\text { biossegurança para prevenção } \\
\text { de acidentes do trabalho e } \\
\text { contaminação por riscos } \\
\text { biológicos. }\end{array}$ & $\begin{array}{l}\text { Permitiu identificar a construção de um } \\
\text { mapa de risco valorizando a consciência } \\
\text { do risco aos profissionais de saúde; } \\
\text { acidentes ocupacionais com material } \\
\text { biológico envolvendo profissionais de } \\
\text { saúde na contaminação de doenças } \\
\text { infecciosas; e ações e medidas de } \\
\text { biossegurança na prevenção aos } \\
\text { acidentes por contaminação biológica } \\
\text { aos profissionais de saúde. }\end{array}$ \\
\hline
\end{tabular}

A quinta etapa consistiu na realização da interpretação e discussão dos dados e resultados encontrados que estavam relacionados com o objetivo. O Quadro 4 mostra a construção das categorias detectadas que foram utilizadas na discussão.

Quadro 4. Categorização das Temáticas do Estudo.

\begin{tabular}{|c|c|l|}
\hline Unidade & Categoria & \multicolumn{1}{|c|}{ Título } \\
\hline Temática & & \multicolumn{1}{|c|}{} \\
\hline Ações & Fatores & A produção científica sobre riscos ocupacionais a \\
educativas & associados à & que estão expostos os trabalhadores de \\
para a & ocorrência de & Enfermagem \\
\cline { 3 - 3 } diminuição & acidentes & Influência da exposição a material biológico na \\
das causas & com & adesão ao uso de equipamentos de proteção \\
de riscos de & materiais & individual \\
\hline
\end{tabular}




\begin{tabular}{|c|c|c|}
\hline $\begin{array}{l}\text { Unidade } \\
\text { Temática }\end{array}$ & Categoria & Título \\
\hline \multirow{11}{*}{$\begin{array}{c}\text { acidentes } \\
\text { nos } \\
\text { profissionais } \\
\text { de } \\
\text { Enfermagem } \\
\text { na Unidade } \\
\text { de Terapia } \\
\text { Intensiva }\end{array}$} & \multirow[t]{5}{*}{$\begin{array}{l}\text { biológicos } \\
\text { em UTI }\end{array}$} & $\begin{array}{l}\text { As crenças dos trabalhadores de saúde nos } \\
\text { acidentes de trabalho com exposição a fluido } \\
\text { biológico: pesquisa descritiva }\end{array}$ \\
\hline & & $\begin{array}{l}\text { Biossegurança em uma unidade de terapia intensiva } \\
\text { a percepção da equipe de Enfermagem }\end{array}$ \\
\hline & & $\begin{array}{l}\text { Saúde ocupacional: analisando os riscos } \\
\text { relacionados à equipe de Enfermagem numa } \\
\text { unidade de terapia intensiva }\end{array}$ \\
\hline & & $\begin{array}{l}\text { Acidentes com materiais perfurocortantes } \mathrm{e} \\
\text { biológicos no ambiente hospitalar: análise da } \\
\text { exposição ao risco e medidas preventivas }\end{array}$ \\
\hline & & $\begin{array}{l}\text { Acidentes de trabalho com material biológico entre } \\
\text { os profissionais de saúde }\end{array}$ \\
\hline & \multirow{6}{*}{$\begin{array}{c}\text { Não } \\
\text { utilização das } \\
\text { precauções } \\
\text { padrões } \\
\text { pelos } \\
\text { profissionais } \\
\text { de } \\
\text { Enfermagem }\end{array}$} & $\begin{array}{l}\text { Investigação de acidentes biológicos entre } \\
\text { profissionais da equipe multidisciplinar de um } \\
\text { hospital }\end{array}$ \\
\hline & & $\begin{array}{l}\text { Influência da exposição a material biológico na } \\
\text { adesão ao uso de equipamentos de proteção } \\
\text { individual }\end{array}$ \\
\hline & & $\begin{array}{l}\text { Biossegurança em uma unidade de terapia intensiva } \\
\text { a percepção da equipe de Enfermagem }\end{array}$ \\
\hline & & $\begin{array}{l}\text { Saúde ocupacional: analisando os riscos } \\
\text { relacionados à equipe de Enfermagem numa } \\
\text { unidade de terapia intensiva }\end{array}$ \\
\hline & & $\begin{array}{l}\text { Acidentes com materiais perfurocortantes e } \\
\text { biológicos no ambiente hospitalar: análise da } \\
\text { exposição ao risco e medidas preventivas }\end{array}$ \\
\hline & & $\begin{array}{l}\text { A importância de medidas de biossegurança como } \\
\text { prevenção de acidentes do trabalho através da } \\
\text { identificação de riscos biológicos no mapa de risco }\end{array}$ \\
\hline
\end{tabular}




\begin{tabular}{|c|c|c|}
\hline $\begin{array}{l}\text { Unidade } \\
\text { Temática }\end{array}$ & Categoria & Título \\
\hline & & $\begin{array}{l}\text { Acidentes de trabalho com material biológico entre } \\
\text { os profissionais de saúde }\end{array}$ \\
\hline & \multirow{9}{*}{$\begin{array}{c}\text { Medidas } \\
\text { preventivas } \\
\text { para a } \\
\text { diminuição } \\
\text { da exposição } \\
\text { dos } \\
\text { profissionais } \\
\text { de } \\
\text { Enfermagem } \\
\text { aos riscos de } \\
\text { acidentes } \\
\text { com } \\
\text { materiais } \\
\text { biológicos. }\end{array}$} & $\begin{array}{l}\text { A produção científica sobre riscos ocupacionais a } \\
\text { que estão expostos os trabalhadores de } \\
\text { Enfermagem }\end{array}$ \\
\hline & & $\begin{array}{l}\text { Investigação de acidentes biológicos entre } \\
\text { profissionais da equipe multidisciplinar de um } \\
\text { hospital }\end{array}$ \\
\hline & & $\begin{array}{l}\text { Influência da exposição a material biológico na } \\
\text { adesão ao uso de equipamentos de proteção } \\
\text { individual }\end{array}$ \\
\hline & & $\begin{array}{l}\text { As crenças dos trabalhadores de saúde nos } \\
\text { acidentes de trabalho com exposição a fluido } \\
\text { biológico: pesquisa descritiva }\end{array}$ \\
\hline & & $\begin{array}{l}\text { Biossegurança em uma unidade de terapia intensiva } \\
\text { a percepção da equipe de Enfermagem }\end{array}$ \\
\hline & & $\begin{array}{l}\text { Saúde ocupacional: analisando os riscos } \\
\text { relacionados à equipe de Enfermagem numa } \\
\text { unidade de terapia intensiva }\end{array}$ \\
\hline & & $\begin{array}{l}\text { Acidentes com materiais perfuro cortantes } \mathrm{e} \\
\text { biológicos no ambiente hospitalar: análise da } \\
\text { exposição ao risco e medidas preventivas }\end{array}$ \\
\hline & & $\begin{array}{l}\text { A importância de medidas de biossegurança como } \\
\text { prevenção de acidentes do trabalho através da } \\
\text { identificação de riscos biológicos no mapa de risco }\end{array}$ \\
\hline & & $\begin{array}{l}\text { Acidentes de trabalho com material biológico entre } \\
\text { os profissionais de saúde }\end{array}$ \\
\hline
\end{tabular}

Após a realização da análise sistemática dos conteúdos, na quinta etapa foram agrupados os conteúdos dos artigos em dados semelhantes e emergiu uma unidade temática: ações educativas para a diminuição das causas de risco de 


\section{Saúde Funcional}

acidentes nos profissionais de Enfermagem na Unidade de Terapia Intensiva, e três categorias: Categoria 1: Fatores associados à ocorrência de acidentes com materiais biológicos em UTI; Categoria 2: A não utilização das precauções-padrão pelos profissionais de Enfermagem; Categoria 3: Medidas preventivas para a diminuição à exposição dos profissionais de Enfermagem aos acidentes com materiais biológicos.

Mediante a busca, os dados analisados na pesquisa, conforme o método, enquadraram-se nessa fase no nível 4, que contempla as evidências de estudos descritivos (não experimentais) ou com abordagem qualitativa.

Pela análise dos dados nessa revisão foi possível observar, contar, somar, descrever e qualificar os dados, o que, segundo Miranda e Stancato ${ }^{7}$, possibilita aglomerar o conhecimento através da temática estudada.

Com a realização da interpretação, discussão dos dados e resultados encontrados, na sexta etapa foi configurada a síntese do conhecimento sobre as ações educativas à diminuição dos riscos de acidentes biológicos nos profissionais de saúde na Unidade de Terapia Intensiva ${ }^{8}$.

\section{DISCUSSÃO}

\section{As ações educativas para a diminuição das causas de riscos de acidentes nos profissionais de enfermagem na unidade de terapia intensiva}

Categoria 1: Fatores associados à ocorrência de acidentes com materiais biológicos em UTI

Entre os fatores associados à ocorrência de acidentes com materiais biológicos no descarte inadequado de utensílios contaminados e perfurocortantes, foram relacionados a não utilização de equipamentos de proteção individual durante a assistência direta, o uso de dispositivos inseguros, entre outros ${ }^{9}$.

Em uma pesquisa, com objetivo de identificar os riscos ocupacionais dos profissionais de Enfermagem no ambiente hospitalar, pontuou-se como causa de acidentes com materiais perfurocortantes e biológicos nos profissionais mais antigos, a educação permanente insuficiente. Para resolução do problema, seria necessária a 


\section{Saúde Funcional}

supervisão contínua e sistemática da prática, percepção individual e valorização das ações preventivas ${ }^{10}$.

A Unidade de Terapia Intensiva é complexa, com elevado risco à equipe de Enfermagem, em função da manipulação de equipamentos e objetos que poderiam estar contaminados com sangue e secreções corporais. Contudo, as ameaças poderiam ser evitadas pelos profissionais que cuidavam dos pacientes, porém descuidavam da própria proteção ${ }^{11}$.

Observamos fatores estressantes com o grau de complexidade das ações desenvolvidas e o sofrimento psíquico causado pelo contato direto com a dor e o sofrimento iminente de morte, que poderiam afetar o desempenho profissional de Enfermagem, o que acarretava falhas na percepção e dificuldade de concentração nas tarefas executadas ${ }^{12}$.

No estudo realizado com a equipe de Enfermagem de uma Unidade de Terapia Intensiva de um hospital público no estado do Ceará, foram analisados os riscos ocupacionais relacionados aos funcionários, que constatavam a multiplicação dos acidentes pelo fato de ser um ambiente crítico e estressante, em que os pacientes necessitavam de cuidados intensivos ${ }^{3}$.

Alguns estudos tiveram como causas o número insuficiente de profissionais, além das crenças do acidente não ocorrer com o próprio, a sobrecarga exaustiva da jornada de trabalho, ausência de questionamentos quanto aos riscos que estariam expostos no cotidiano, a qualidade de assistência aos pacientes e o autocuidado ${ }^{11}$, $13,14,15$

Pontos relevantes expostos pelos autores foram a importância para a tomada de medidas preventivas que diminuiriam as exposições aos riscos biológicos, como a falta de atenção e inobservância de medidas preventivas e percepção individual sobre o acidente, o desconhecimento das causas de infecção e a desconsideração das precauções-padrão e sensibilização sobre o assunto ${ }^{16}$.

Cabe destacar que os acidentes que envolviam funcionários ocorreram devido ao uso de materiais perfurocortantes, fato este que preocupa os estudiosos em relação à qualidade dos dispositivos que são manipulados, principalmente os contaminados, em decorrência das ameaças à saúde que poderiam acarretar ${ }^{14}$.

Os motivos determinados para a ocorrência de exposição dos trabalhadores aos materiais biológicos foram a resistência ao uso de Equipamentos de Proteção 
Individual (EPIs), descarte inadequado de objetos infectados e produtos sem 0 dispositivo de segurança $3,9,11,12,13$.

Dessa forma, o risco entre os profissionais aumentavam através da atuação em unidades complexas pelas possibilidades de acidentes, sejam físicos, químicos ou biológicos, percebidos nas complexidades das atividades desenvolvidas como no suporte tecnológico e o conhecimento referido dos funcionários ${ }^{3,9}$.

Por estas razões, seria importante o planejamento das medidas de proteção, a partir do conhecimento das fontes de exposição dos riscos biológicos e os reservatórios teriam por constituições pessoas, animais, objetos e substâncias, assim como as vias de transmissão e de entradas ${ }^{5}$.

Categoria 2: A não utilização das precauções-padrão pelos profissionais de Enfermagem

Em uma pesquisa, constatou-se que as medidas para prevenção de acidentes de trabalho e contaminações por riscos biológicos foram evidenciadas nos profissionais de saúde pelo desconhecimento das ameaças expostas. Porém estes sabiam da importância das medidas preventivas de biossegurança para proteção, mas somente utilizavam essas medidas por serem normas impostas pelas instituições ${ }^{15}$.

A equipe de Enfermagem é uma das principais categorias expostas a situações de perigo e isso acontece pelo fato de estarem em contato constante com os riscos ocupacionais ${ }^{3}$.

Fatores que contribuíram para a exposição ocupacional aconteciam no cotidiano do serviço de Enfermagem. Em outra pesquisa, cujas situações de risco deveriam ser percebidas nos procedimentos e ações desenvolvidas na clientela e no ambiente assistencial devido à ausência de EPIs apropriados, muitos trabalhadores utilizavam roupas e calçados incorretos no meio insalubre e muitas vezes a própria estrutura não concordava com as medidas de segurança ${ }^{3,13}$.

Mas em outra produção científica, os profissionais obtiveram o conhecimento da importância das medidas preventivas e o uso de equipamentos de proteção padrão para as instituições de saúde, porém a maioria não fazia o uso e quando usavam era de forma incorreta. Assim a educação continuada para qualificação, instrução e reforços poderiam diminuir as ocorrências dos acidentes ${ }^{9}$. 
Em um estudo foi possível caracterizar os acidentes ocupacionais com material biológico no período de 2000-2006 em dois hospitais-escola do interior paulista, na constatação de que os profissionais de saúde foram resistentes e negligentes ao uso do EPI, mesmo com os avanços que envolviam os riscos de contaminação após o advento da AIDS ${ }^{11}$.

Alguns autores descreveram a adesão do equipamento de proteção individual entre grupos de Enfermeiros e técnicos de Enfermagem, sobre exposições aos materiais biológicos como fator determinante das mudanças comportamentais ao uso de EPIs, sem excluir o risco de acidentes e adquirir doenças ocupacionais ${ }^{12,14}$.

Assim, uma das causas à ocorrência de exposição aos itens biológicos com consequência de acidentes acontecia devido à resistência quanto a não utilização das precauções-padrão para prevenções, além da falta de credibilidade na eficácia das medidas de proteção individual, dificuldade de capacitação profissional, desinteresse dos trabalhadores, esquecimento, pressa, recursos financeiros insuficientes e estrutura organizacional insatisfatória ${ }^{9}$.

Contudo, os autores têm o discurso de que acidentes com materiais biológicos não determinam a adesão ao uso dos equipamentos de proteção e adoção de comportamento preventivo, mas o que determina a adesão às técnicas preventivas se dá por medo de se infectar, o que tornar um indicador de conduta de segurança que contribuiu para diminuição da ocorrência de acidentes e mudança de postura profissional para eliminação das contaminações ${ }^{4 "}$

Categoria 3: Medidas preventivas para a diminuição da exposição dos profissionais de Enfermagem aos acidentes com materiais biológicos

Observamos que todos os autores foram unânimes ao concluírem que medidas preventivas para minimizar a exposição dos profissionais de saúde aos riscos biológicos, educação continuada e, ações e programas de prevenção aos acidentes biológicos deveriam ser realizadas pelas instituições empregadoras com os profissionais da saúde e a equipe de Enfermagem, por estarem envolvidos com a assistência direta aos clientes ${ }^{1}$. 
Assim, a falta de adoção de medidas preventivas, como o uso de EPls, relatada nos estudos listados, destacava a não utilização das precauções-padrão pelos profissionais de Enfermagem, ficando expostos aos riscos e ocorrências de acidentes com materiais biológicos, que deveriam ser abordados pelas equipes de educação continuada ${ }^{10}$.

Autores retratavam o uso de equipamentos de proteção de segurança como barreira primária de contenção, tais como óculos, luvas, máscaras e capotes, destinados a proteger o trabalhador dos riscos que seriam expostos ${ }^{5}$.

Já outros relatavam o uso de EPIs como medida preventiva para a exposição dos elementos biológicos, e que os estudos, realizados através de revisão integrativa, citaram o uso de equipamentos de proteção individual com a maior facilidade para evitar acidentes ${ }^{15}$.

Dessa forma, conhecer o perigo é fundamental ao desenvolvimento de mecanismos de controle, proteção adequada e promoção da própria saúde dos colaboradores ${ }^{4}$.

Por isso, o uso desses acessórios é necessário para realizar a prevenção primária do contato com ferramentas de maneira segura na redução à exposição ocupacional a sangue e outros fluidos orgânicos, cuja equipe estava exposta ${ }^{14}$.

É vital a importância do uso dos instrumentos para a prevenção de acidentes com materiais biológicos, porém o papel das empresas de saúde empregadoras quanto ao fornecimento de equipamentos de segurança, proteção individual e coletiva deveria ser destacado. Para tal, são necessários treinamentos para o uso correto de tais produtos ${ }^{3,11}$.

A educação continuada segue as recomendações e normas da biossegurança, tendo a possibilidade de intervenção à adoção e implementação das medidas de segurança que visavam a minimização da exposição aos riscos ocupacionais e biológicos ${ }^{3,5}$.

Para alcançar condições de trabalho adequadas e seguras, os trabalhadores de Enfermagem precisam estar tecnicamente capacitados para desempenho das funções e participar da elaboração das políticas de trabalho às quais se diz respeito ${ }^{15}$.

No entanto, é importante que seja elaborado e executado um programa de educação continuada, que aborde as questões da exposição e acidentes com materiais biológicos, com busca de esclarecimentos sobre a importância das medidas 


\section{Saúde Funcional}

de precaução-padrão e normas de biossegurança, vacinação e notificação de acidentes, que seriam ministrados aos profissionais da área, visando aquisições de conhecimentos dos funcionários, para consequentemente reduzirem eventos pelas equipes nos hospitais ${ }^{9}$.

Vale ressaltar a amplitude dos conceitos de biossegurança como o campo de ação, que permeava ações voltadas para prevenção, minimização ou eliminação de riscos, além da preocupação com a saúde do homem e do meio ambiente ${ }^{17}$.

\section{CONCLUSÃO}

Na revisão destas publicações, foram constatadas as causas da exposição da equipe de Enfermagem aos agentes biológicos, os motivos pelos quais os acidentes aconteciam e as medidas preventivas que poderiam auxiliar na diminuição dos acidentes ocupacionais.

A Unidade de Terapia Intensiva é considerada um ambiente instável e estressante, em que a clientela pode ser entendida com o risco iminente de morte, cujas atividades exercidas pela equipe de Enfermagem são complexas, com a possibilidade de ocorrerem elevados números de riscos ocupacionais.

Durante a pesquisa, percebeu-se o estado psicológico dos funcionários nos artigos coletados, que ficavam afetados pelo cuidado direto com o cliente, com provável incidência de falha na percepção quanto à exposição aos riscos, que em sua maioria envolvia a dificuldade de concentração no desenvolvimento das tarefas.

Além desses motivos, as causas da exposição aos materiais biológicos e, por consequência, os acidentes, estavam nas crenças dos profissionais de que nenhum evento iatrogênico iria acontecer com o mesmo, pela dupla jornada de trabalho, estresse, falta de valorização das ações preventivas, desconhecimento do perigo de infecção, desconsideração das precauções-padrão, entre outras possíveis causas.

Os acidentes que envolveram materiais biológicos decorriam da manipulação de materiais perfurocortantes, do descarte inadequado de materiais contaminados e da resistência dos profissionais de saúde quanto ao uso do EPI.

Quanto aos profissionais em relação a não utilização das precauções-padrão, foi constatado que muitos não utilizavam o EPI durante a assistência ao paciente, e 


\section{Saúde Funcional}

quando usavam, faziam de forma inadequada e ficariam acessíveis aos riscos ocupacionais.

Uma parte dos profissionais de Enfermagem aderiu ao uso dos EPls após exposição com materiais perfuro cortantes com receio de se infectar; já outros, mesmo após o acontecimento com materiais biológicos, faziam uso de medidas preventivas de forma temporária.

As informações colhidas nesta revisão integrativa mostraram que a exposição aos materiais biológicos e aos acidentes ocupacionais envolveram os profissionais de Enfermagem que eram passíveis de prevenção e possibilitavam uma diminuição dos acidentes de trabalho.

Para tal precaução, as empresas de saúde empregadoras deveriam realizar fornecimento de equipamentos individuais e coletivo de qualidade e ter funcionários qualificados para realizar as orientações de prevenção de acidentes ao pessoal da Enfermagem envolvido na assistência direta aos clientes, o que auxiliaria na diminuição de acidentes evitáveis.

As ações e programas de prevenção aos acidentes biológicos e educação continuada deveriam demonstrar os riscos aos quais os profissionais estavam submetidos no ambiente hospitalar e principalmente nas UTIs.

As equipes de educação continuada deveriam treinar com instruções quanto ao uso adequado dos equipamentos de proteção, adoção das normas de biossegurança, a importância na assistência, além de qualificação do uso correto dos dispositivos de segurança.

Esperamos que com a disseminação desse estudo, os profissionais de Enfermagem que tiverem acesso a essa pesquisa reflitam em suas ações, adotem medidas preventivas eficazes para auxiliar na diminuição dos riscos evitáveis da exposição de acidentes biológicos, objetivando a promoção da saúde do trabalhador.

\section{AGRADECIMENTOS}

Os autores agradecem a Hugo Alexandre Henriques Sartunino, das Faculdades Integradas Campograndese, do curso de graduação em Letras Português/Inglês, 
Artigo de Revisão

Saúde Funcional

pelas contribuições, com a revisão ortográfica e gramatical de língua portuguesa e inglesa.

\section{REFERÊNCIAS}

1. Oliveira AC, Paiva MHRS. Análise dos acidentes ocupacionais com material biológico entre profissionais em serviços de atendimento pré-hospitalar. Rev. LatinoAm. Enfermagem, Ribeirão Preto 2013;21(1):309-15.

2. Nishide VM, Benatti MCC. Riscos ocupacionais entre trabalhadores de enfermagem de uma unidade de terapia intensiva. Rev. Esc. Enfermagem USP, São Paulo 2004;38(4):406-14.

3. Leitão IMTA, Fernandes AL, Ramos IC. Saúde ocupacional: analisando os riscos relacionados à equipe de enfermagem numa unidade de terapia intensiva. Cienc. Cuid. Saúde, Ceará 2008;7(4):476-84.

4. Bonini AM, Zeviani CP, Facchin LT, Gir E, Canini SRMS. Exposição ocupacional dos profissionais de enfermagem de uma unidade de terapia intensiva a material biológico. Rev. Eletr. Enf. 2009;11(3):658-64.

5. Brasil. Mistério do Trabalho e Emprego. Riscos Biológicos - Guia Técnico. Os riscos biológicos no âmbito da Norma Regulamentadora №. 32. Mistério do Trabalho e Emprego. Brasília, 2008.

6. Pompeo DA, Rossi LA, Galvão CM. Revisão integrativa: etapa inicial do processo de validação de diagnóstico de enfermagem. Acta Paulista de Enfermagem, São Paulo 2009;22(4):434-38.

7. Mendes KDS, Silveira RCCP, Galvão CM. Revisão Integrativa: método de pesquisa para incorporação de evidências na saúde e na enfermagem. Texto Contexto Enf., Florianópolis 2008;17(4):758-64.

8. Souza MT, Silva MD, Carvalho R. Revisão integrativa: o que é e como fazer. Einstein 2010;8(1) (Pt 1):102-6. 
9. Silva MR, Cortez EA, Valente GSC. Acidente com materiais perfuro cortantes e biológicos no ambiente hospitalar: análise da exposição ao risco e medidas preventivas. Revista de pesquisa: Cuidado é Fundamental Online, Rio de Janeiro 2011;3(2):1856-72.

10. Correa CF, Donato M. Biossegurança em uma unidade de terapia intensiva: a percepção da equipe de enfermagem. Esc. Anna Nery, Rio de Janeiro 2007:11(2):180-95.

11. Magagnini MAM, Miotto LB, Serradilha AFZ. Acidentes de trabalho com material biológico entre os profissionais de saúde. CuidArte Enfermagem, São Paulo 2008:2(1):53-60.

12. Ribeiro LCM, Souza ACS, Neves HCC, Munari DB, Medeiros M, Tipple AFV. Influência da exposição a material biológico na adesão ao uso de equipamentos de proteção individual. Cienc. Cuid. Saúde, Goiânia 2010:9(2):325-32.

13. Wall ML, Miranda FMD, Sarquis LMM, Labronici LM, Cruz EDA. As crenças dos trabalhadores de saúde nos acidentes de trabalho com exposição a fluido biológico: pesquisa descritiva. Online Brazilian Journal of Nursing, Paraná 2011;10(1):207-19.

14. Castro MR, Farias SNP. A produção científica sobre riscos ocupacionais a que estão expostos os trabalhadores de enfermagem. Esc. Anna Nery, Rio de Janeiro 2008;12(2):364-9.

15. Metello FC, Valente GSC. A importância de medidas de biossegurança como prevenção de acidentes do trabalho através da identificação de riscos biológicos no mapa de risco. Revista de Pesquisa: Cuidado é Fundamental Online, Rio de Janeiro 2012;4(3):2338-48.

16. Miranda EJP, Stancato K. Riscos à saúde de equipe de enfermagem em Unidade de Terapia Intensiva: proposta de abordagem integral da saúde. Revista Brasileira de Terapia Intensiva, São Paulo 2008;20(1):68-76. 
Artigo de Revisão

Saúde Funcional

17. Câmara PF, Lira C, Junior BJS, Vilella TAS, Hinrichsen SL. Investigação de acidentes biológicos entre profissionais da equipe multidisciplinar de um hospital. Rev. Enferm: UERJ, Rio de Janeiro 2011;19(4):583-96. 